\title{
ENDOSCOPIC DACRYOCYSTORHINOSTOMY [DCR] WITH MEROCEL PACK IN THE LACRIMAL SAC- AN INNOVATIVE TECHNIQUE
}

\author{
Ike Thomas ${ }^{1}$, Pramod Thomas ${ }^{2}$, R. C. Kapoor ${ }^{3}$
}

${ }_{1}^{1}$ Assistant Professor, Department of ENT, Believer's Church Medical College, Thiruvalla, Kerala, India.

${ }^{2}$ Associate Professor, Department of Community Medicine, Believer's Church Medical College, Thiruvalla, Kerala, India.

${ }^{3}$ Consultant, Badr Al-Sama Hospital, Oman.

\begin{abstract}
BACKGROUND

DCR is a surgical procedure performed to create a new tear drainage pathway between the eye and the nose when the tear drain becomes obstructed at the level of nasolacrimal duct, which is the commonest site of blockage in lacrimal apparatus. This technique of DCR with Merocel pack in the lacrimal sac completely avoids any complications like lacrimal pump failure, canthal erosion, canthal cheese wiring, although few patients exhibit complications like granuloma, synechiae/ adhesions and foreign body sensation inside the nose for few days. Patients are relieved of epiphora/ mucocele with less operative time and post-operative care.
\end{abstract}

The objective of the study is to describe the various complications, which can occur in endoscopic DCR procedure.

\section{MATERIALS AND METHODS}

It is a descriptive study. We enrolled 30 participants with nasolacrimal duct obstruction presenting with epiphora, mucocele and palpable lacrimal sac and were managed with endoscopic DCR with a 'Merocel pack in the sac technique.' The present study was conducted at the Ministry of Health Hospital, Rustaq, Sultanate of Oman, during 2007 to 2014. The sample size was taken for convenience during the study.

\section{RESULTS}

Results were compared with standard external DCR and endoscopic DCR with silicone stents. All patients were operated under general anaesthesia. Participants were followed for 6 months and outcomes (Absence of epiphora and the patency of sac) and complications (lacrimal pump failure, canthal erosion, canthal cheese wiring granuloma, synechiae/ adhesion and foreign body sensation) were measured. Lacrimal sac was opened and the Merocel pack was kept in the sac $(1 \mathrm{~cm} \times 0.5 \mathrm{~cm})$ for 10 days and then removed. The present innovative technique gave good results ( $p$-value $<0.0001$ ), took less post-operative time and fewer postoperative complications.

\section{CONCLUSION}

Endoscopic DCR with 'Merocel pack in the sac technique' is an excellent novel technique for the treatment of epiphora and mucocele due to nasolacrimal duct obstruction. It should be the treatment of choice in view of maintenance of long-term results, patient compliance and cost effectiveness.

\section{KEY WORDS}

Dacryocystorhinostomy, Merocel Pack, Sac.

HOW TO CITE THIS ARTICLE: Thomas I, Thomas P, Kapoor RC. Endoscopic dacryocystorhinostomy [DCR] with Merocel pack in the lacrimal sac- an innovative technique. J. Evolution Med. Dent. Sci. 2018;7(36):4000-4003, DOI: 10.14260/jemds/2018/893

\section{BACKGROUND}

Dacryocystorhinostomy [DCR] is the surgical procedure performed while patients present with epiphora, mucocele and palpable lacrimal sac. Tear drain becomes obstructed at the level of nasolacrimal duct (commonest site of blockage in lacrimal apparatus), DCR will create a new tear drainage pathway between the eye and the nose.

Nasolacrimal duct obstruction occurs either congenitally or from various acquired causes like facial trauma, chronic environmental allergies, toxicity from chemotherapeutic

'Financial or Other Competing Interest': None.

Submission 29-06-2018, Peer Review 21-08-2018,

Acceptance 27-08-2018, Published 03-09-2018.

Corresponding Author:

Dr. Ike Thomas,

Kizhake Veedu, Pamayely P. 0.

Kottarakara-691532, Kollam,

Kerala, India.

E-mail: drikethomas@gmail.com

DOI: $10.14260 / \mathrm{jemds} / 2018 / 893$

\section{(c) (1) $(9)$}

drugs, topical medications, long-standing sinus disease or following sinonasal surgery.[1,2] Dacryocystitis mostly results from descending inflammation from the eye or ascending inflammation from the nose.[2] Repeated occurrence of inflammatory reactions ends up with structural, epithelial and subepithelial changes leading to total fibrous closure of lumen.[2] DCR can be performed externally or endoscopically through nose. History of DCR stretches back nearly 2000 years. It was Celsus who described about DCR in first century. [3] Galen described about DCR in second century. Toti described about external DCR in 1904.[4] It was Caldwell who described transnasal DCR in 1983.[5] McDonogh and Meiring described the endoscopic DCR in 1989.[6] With the advent of endoscopes and audio-visual aids, endoscopic DCR has gained much popularity.

DCR can be done externally or endoscopically with or without using silicone stent. Endoscopic DCR has many advantages over external DCR like avoiding scar over the face, avoiding the need of division of medial canthal ligament and preservation of orbicularis oculi muscle pump action of the lacrimal sac.[1,2] Endoscopic DCR also enables correction 
of associated pathology like deviated nasal septum, chronic rhinosinusitis and polyps at the same time.[2] Pyoceles and acute infection of nasolacrimal duct with or without skin involvement can be drained safely endoscopically, thereby reducing risk of intracranial extension.[2] Closure of the rhinostomy opening was considered a major factor of failure of external DCR, while fibrosis of cutting edges of medial wall of lacrimal sac and reposition of nasal mucosa are common causes of failure of endoscopic DCR without stent.[1] With stents canthal erosion and canthal cheese wiring are seen.[1] Our technique of keeping Merocel pack in the sac for 10 days after opening the sac and drainage of pus is an innovative technique with patent drainage of tear into the nose. This technique of keeping Merocel pack in the lacrimal sac for 10 days heals the cut margins of the sac, hence prevents fibrosis and blockage of cut ends of the sac. Since there is no stents used, the ends of the stent will not irritate nasal mucosa which leads to synechiae formation, adhesion, foreign body sensation, granuloma formation and epistaxis, especially if the stent is kept inside the nose for long time. The minor complications seen in external DCR such as conjunctival haematoma, trauma to eyelids and periorbital oedema are not seen in our technique.

\section{Objective of the Study}

To describe the various complications, which can occur in endoscopic DCR procedure.

\section{MATERIALS AND METHODS}

It is a descriptive study. We enrolled 30 participants with nasolacrimal duct obstruction presenting with epiphora, mucocele and palpable lacrimal sac and were managed with endoscopic DCR with a 'Merocel pack in the lacrimal sac technique.' The present study was conducted at the Ministry of Health Hospital, Rustaq, Sultanate of Oman, during 2007 to 2014. The sample size was taken for convenience during the study. Participants approached the hospital with chronic dacryocystitis (Epiphora, mucocele, palpable lacrimal sac) were enrolled for endoscopic DCR after screening for the distal nasolacrimal duct obstruction. Those who enrolled were counselled regarding the use of Merocel packs and detailed informed consent was taken. Data on Age, Gender, Side operated and various complications present (lacrimal pump failure, canthal erosion, canthal cheese wiring, granuloma, synechiae/ adhesion and foreign body sensation) were noted at each visit. The patients were followed up on $10^{\text {th }}$ day for Merocel pack removal, 3 weeks, 3 months, 6 months and 1 year post-operatively with nasal endoscopy. If there was any synechiae adhesion or granuloma formation seen in any of the visits, they were tackled in the outpatient department endoscopically.

\section{Surgical Technique}

All patients were operated under general anaesthesia, local decongestion of the nasal mucosa and middle turbinate was done with $4 \%$ Lignocaine with adrenaline solution soaked patties. The site for elevation of the flap was ascertained with the help of bayonet forceps, one prong was kept on the lateral nasal wall outside the distended sac area and the other prong on the mucosal surface of the lateral nasal wall. The area identified was infiltrated with $2 \%$ lignocaine with adrenaline. Following decongestion, the mucoperiosteum over the area anterior to the axilla of middle turbinate was either elevated as a flap or the mucosa overlying the bone was cauterised. The bone was removed using Kerrison rongeurs, drill or by osteotome, depending upon the thickness of the lacrimal bone in that particular patient. After removal of the bone, the lacrimal sac was identified by applying pressure over the sac from the outside. After identification of the sac, a vertical incision was made over the entire vertical extent of the sac and the pus was drained. The lacrimal sac was flushed and a portion of the medial wall of the sac was removed to prevent its subsequent closure. Any deviated nasal septum, polyps, paradoxical turbinate and concha bullosa which prevent the access of the surgery were tackled endoscopically at the same sitting.

A $1 \mathrm{~cm}$ x $0.5 \mathrm{~cm}$ size Merocel pack was used. This Merocel pack is tailor made from the commercially available Merocel nasal packs. A suture tie was placed on the lower end of the pack and this pack was placed inside the sac remnant. This suture tie was taken out through the ala of nose and taped with plaster. The Merocel pack was kept in situ for 10 days and on the 10th post-operative day the Merocel pack was removed from the sac by gently pulling the suture tie.

\section{Statistical Analysis}

P-value $<0.05$ was used to establish the significance. SPSS software version 25 was used.

\section{RESULTS}

30 patients were enrolled into the study over a period of 90 months. There were 8 males [26\%] and 22 females [73\%] [Table 1]. Age of the participants ranged from 30 to 64 with a mean age of 49.04 [SD -9.99]. 12 patients [42\%] were operated on left side and 13 patients [52\%] were operated on right side. Over the period of six months follow- up, we observed $100 \%$ success (p-value $<0.0001$ ). The complications like lacrimal pump failure, canthal erosion and canthal cheese wiring which are common in external DCR was not seen in our study [Table 1]. The complications seen in endoscopic DCR with silicone stents like granuloma formation, synechiae/ adhesion formation and foreign body sensation were less common, less than $16 \%$ [Table 1]. None or very few complications were observed in our series from 3 weeks follow-up onwards [Table 1]. When patients came for 3 weeks to 3 months follow-up, granuloma formation that were found was removed and was completely resolved by 3 months period. Synechiae found were released and by 3 months follow-up onwards synechiae had settled. Foreign body sensation settled immediately after the Merocel pack was removed [Table 1]. The minor complications seen in external DCR such as conjunctival haematoma, trauma to eyelids and periorbital oedema are not seen as the surgery is done endoscopically.

Endoscopic DCR without stents have high proportion of fibrosis of cut ends of the sac and hence cannot maintain the sac patency and tear drainage which leads to recurrence of patient's symptoms. Keeping the Merocel pack in the sac for 10 days aids in complete healing with no fibrosis of the cut ends of the sac, which helps to maintain the sac patency and tear drainage in long run. 


\begin{tabular}{|c|c|c|}
\hline & $\begin{array}{c}\text { No } \\
\text { Frequency (\%) }\end{array}$ & $\begin{array}{c}\text { Yes } \\
\text { Frequency (\%) }\end{array}$ \\
\hline Lacrimal Pump Failure & $30(100 \%)$ & $0(0 \%)$ \\
\hline $\begin{array}{c}\text { Canthal Erosion, } \\
\text { Canthal Cheese Wiring }\end{array}$ & $30(100 \%)$ & $0(0 \%)$ \\
\hline \multicolumn{2}{|c|}{ Granuloma Formation } \\
\hline 10 days & $28(9 \%)$ & $2(8 \%)$ \\
\hline 3 weeks & $28(92 \%)$ & $2(8 \%)$ \\
\hline 6 weeks & $28(92 \%)$ & $2(8 \%)$ \\
\hline 3 months & $30(100 \%)$ & $0(0 \%)$ \\
\hline 6 months & $30(100 \%)$ & $0(0 \%)$ \\
\hline 1 year & $30(100 \%)$ & $0(0 \%)$ \\
\hline Synechiae Formation \\
\hline 3 weeks & $26(84 \%)$ & $4(16 \%)$ \\
\hline 6 weeks & $26(84 \%)$ & $4(16 \%)$ \\
\hline 3 months & $36(84 \%)$ & $4(16 \%)$ \\
\hline 6 months & $30(100 \%)$ & $0(0 \%)$ \\
\hline 1 year & $30(100 \%)$ & $0(0 \%)$ \\
\hline \multicolumn{3}{|c|}{ Foreign Body Sensation } \\
\hline 10 days & $25(80 \%)$ & $5(20 \%)$ \\
\hline 3 weeks & $29(96 \%)$ & $1(4 \%)$ \\
\hline 6 weeks & $30(100 \%)$ & $0(0 \%)$ \\
\hline 3 months & $30(100 \%)$ & $0(0 \%)$ \\
\hline 6 months & $30(100 \%)$ & $0(0 \%)$ \\
\hline 1 year & $30(100 \%)$ & $0(0 \%)$ \\
\hline Table 1. Frequency (\%) level on success rate \\
\hline
\end{tabular}

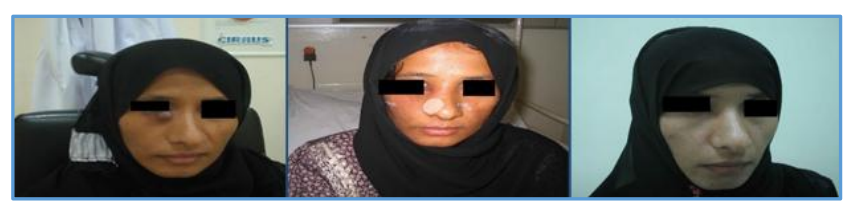

Figure 1. Pre-op, 10th day post-op with Merocel pack in situ and 3 months Post-op

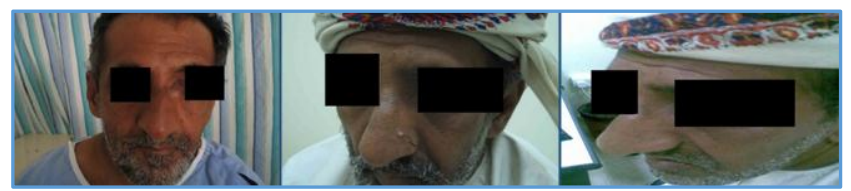

Figure 2. Pre-op, 10th day post-op with Merocel pack in situ and 3 months Post-op

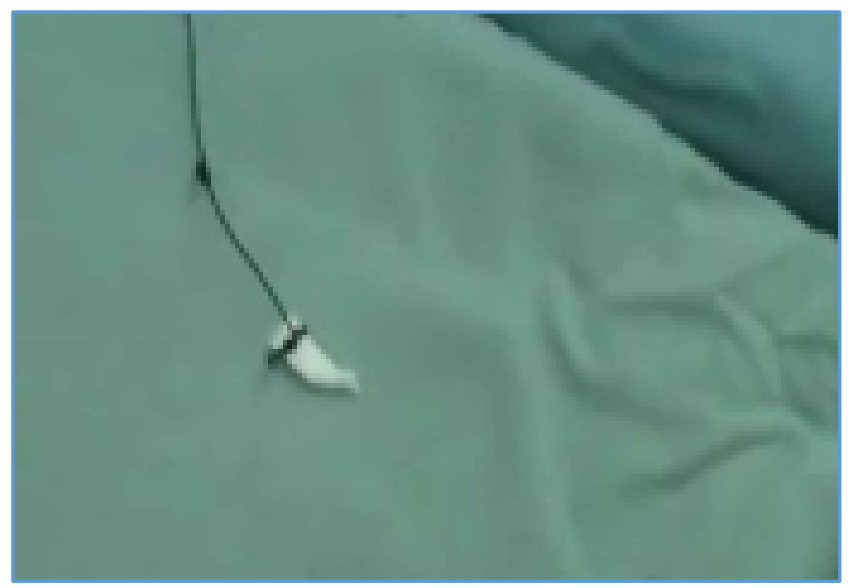

Figure 3. Merocel Pack with Suture Tie

\section{DISCUSSION}

Endoscopic DCR with 'Merocel pack in the sac technique' is an innovative, cost effective, less time consuming surgery with good patient compliance ( $p$-value $=0.0001)$, less complications and good post-operative results. In our series there were no major complications compared to that seen in external DCR like lacrimal pump failure, canthal erosion and canthal cheese wiring. One study reported minor complications like orbital swelling, orbital haemorrhage and ecchymosis.[7,8,9,10,11,12,13,14] Our study did not find any of such complications of external DCR. Granuloma formation, synechiae/ adhesion formation and foreign body sensation seen were self-limiting and settled by 3 months' time. During serial visits if any were present, they were removed or released and later usually settles by itself. In any case, these complications were not seen in our cases after 3 months. The foreign body sensation usually settled with removal of Merocel pack. The Merocel pack in the sac for 10 days prevents synechiae between the opposing walls and hence sac patency is maintained, and patients get relieved of their complaints like epiphora and mucocele formation. Keeping Merocel pack in the lacrimal sac is less traumatic, easy technique and hence less time consuming which increases cost effectiveness and patient compliance.

\section{CONCLUSION}

Endoscopic DCR with 'Merocel pack in the sac technique' is an excellent novel technique for the treatment of epiphora and mucocele due to nasolacrimal duct obstruction. It should be the treatment of choice in view of maintenance of long-term results, patient compliance and cost effectiveness.

\section{REFERENCES}

[1] Jyothi AC, Kumar A, Chiluveru P. Endoscopic dacryocystorhinostomy: our experience. Int J Otorhinolaryngol Head Neck Surg 2016;2(4):254-7.

[2] Ray B, Datta D, Roy P. Long term success of Endo DCR with silicone tube catheter (STC) versus Endo DCR without STC: a comparative study. Bengal J Otolaryngol Head Neck Surg 2016;24(2):88-93.

[3] Chandler PA. Dacryocystorhinostomy. Trans Am Ophthalmol Soc 1936;34:240-63.

[4] Toti A. Nuovo metodo conservatore di cura radical delle suprazioni chroniche del sacco lacrimale. Clin Mod Firenze 1904;10:385-9.

[5] Metson R, Woog JJ, Puliafito CA. Endoscopic laser dacryocystorhinostomy. Laryngoscope 1994;104(3 Pt 1):269-74.

[6] McDonogh M, Meiring JH. Endoscopic transnasal dacryocystorhinostomy. J Laryngol Otol 1989;103(6):585-7.

[7] Maini S, Raghava N, Youngs R, et al. Endoscopic endonasal laser versus endonasal surgical dacrocystorhinostomy for epiphora due to nasolacrimal duct obstruction: prospective, randomized, controlled trail. J Laryngol Otol 2007;121(12):1170-6.

[8] Walker RA, Al-Ghoul A, Conlon MR. Comparison of non-laser non-endoscopic endonasal dacrocystorhinostomy with external dacrocystorhinostomy. Can J Ophthalmol 2011;46(2):191-5. 
[9] Machin SJ, Laguarta CJM, De Gregorio AMA, et al. Lacrimal duct obstruction treated with nasolacrimal stent. Arch Soc Esp Oftalmol 2003;78(6):315-8.

[10] Bogdanici C, Lupascu C, Halunga M. Complications after catheterization of nasolacrimal duct. Oftalmologia 2002;55(4):39-42.

[11] Beloglazov VG, Atokova EL, Malaeva LV, et al. Intubation granulomas of the lacrimal ducts in patients with silicone implants. Vestn Oftalmol 1998;114(5):29-32.
[12] Allenn K, Berlin AJ. Dacrocystorhinostomy failure: association with nasolacrimal silicone intubation. Ophthalm Surg 1989;20(7):486-9.

[13] Walland MJ, Rose GE. The effect of silicone intubation and on failure and infection rates after dacrocyst orhinostomy. Ophthalmic Surg 1994;25(9):597-600.

[14] Unlu HH, Ozturk F, Mutlu C, et al. Endoscopic dacrocystorhinostomy without stents. Auris Nasus Larynx 2000;27(1):65-71. 